\title{
Synthesis of Siloxane-polyimide Copolymer with Low Birefringence and Low Loss for Optical Waveguide
}

\author{
Noor Farahin Mohd Ibrahim, ${ }^{1}$ Mohamad Riduwan Ramli, ${ }^{1}$ Arjulizan Rusli, ${ }^{1}$ \\ Mohd Kamil Abd Rahman ${ }^{2}$ and Zulkifli Ahmad ${ }^{1 *}$ \\ ${ }^{1}$ Silicone Polymer Research Group, School of Materials and Mineral Resources \\ Engineering, Universiti Sains Malaysia, Engineering Campus, \\ 14300 Nibong Tebal, Pulau Pinang, Malaysia \\ ${ }^{2}$ Photonics Lab, Faculty of Applied Sciences, Universiti Teknologi MARA, \\ 40450 Shah Alam, Selangor, Malaysia \\ *Corresponding author: zulkifli@usm.my
}

Published online: 25 December 2019

To cite this article: Mohd Ibrahim, N. F. et al. (2019). Synthesis of siloxane-polyimide copolymer with low birefringence and low loss for optical waveguide. J. Phys. Sci., 30(Supp. 2), 103-113, https://doi.org/10.21315/jps2019.30.s2.9

To link to this article: https://doi.org/10.21315/jps2019.30.s2.9

\begin{abstract}
Optical properties of fluorinated polysiloxane-co-polyimide (PI-ATPDMS) were investigated based on the molecular structure and compared with the pure polyimide (PI) at $1550 \mathrm{~nm}$ radiation. The refractive index of the copolymers was slightly reduced by $3.5 \%$ whilst the birefringence was reduced by $0.37 \%$ respectively compared to $P I$. They are highly transparent at near infrared (IR) region with light transmittance above $90 \%$ at visible region. An asymmetry planar waveguide was fabricated which recorded a respectable low

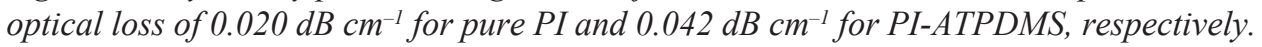
The excellent optical properties displayed by these series of materials established their viable application as waveguide material at $1550 \mathrm{~nm}$ wavelength.
\end{abstract}

Keywords: Fluorinated polyimide, fluorinated polyimide-siloxane copolymer, optical loss, birefringence, waveguide

\section{INTRODUCTION}

Several polymers such as acrylates, polyimides and olefins have been attempted for use during waveguide fabrication. Besides polymethylmethacrylate (PMMA) and SU8, fluorinated polyimide have been a popular theme in designing optical waveguide for low transmission loss. ${ }^{1,2}$ Several works have substantiated that replacement of C-H with $\mathrm{C}$-F in polyimide reduced absorption at near infrared (NIR) 
telecommunication region. ${ }^{3-9}$ Han et al. worked on copolymerisation of different monomers especially in adding halogen group to improve optical properties for use as waveguide which exhibited low loss of less than $0.4 \mathrm{~dB} \mathrm{~cm}^{-1}$ at $1550 \mathrm{~nm} .^{5}$ Meanwhile, a fluorinated polyurethane-imide as the core and SU-8 as the cladding displaying the radiation loss $1.5-1.7 \mathrm{~dB} \mathrm{~cm}^{-1}$ at $1550 \mathrm{~nm}$ has been designed. ${ }^{10}$ Another popular polymeric material used is polysiloxane which possesses good thermal properties, high transparency, low refractive index and poor absorbancy at NIR region. ${ }^{11-13}$ An early optical work of polysiloxane was performed by Flipsen et al.who obtained an optical loss of $0.98 \mathrm{~dB} \mathrm{~m}^{-1}$ at $780 \mathrm{~nm}$ wavelength radiation with refractive index in the range 1.475 to $1.483 .^{2}$ The incorporation of silicone into the polymer waveguide was further explored as in the work of Hegde et al. ${ }^{14}$ They studied the polysiloxane waveguide system at wavelength $850 \mathrm{~nm}$ and 1310 $\mathrm{nm}$ whose optical loss was found to be contributed by the local density fluctuation in the cured silicone during different levels of curing. Specific wavelength of interest in this work is $1550 \mathrm{~nm}$, which is typical emission wavelength of datacom lasers for short link applications. ${ }^{15}$

Polyimide-siloxane copolymer offer synergetic advantages of properties between viable processability of siloxane and thermal stability of polyimide. These include chain flexibility and free volume. The flexibility of siloxane can induce free volume which can ease processability of rigid backbone of polyimide without giving significant change in thermal stability of polyimide. The present work seeks to establish optical properties of polyimide-siloxane copolymers bearing fluorine functionality henceforth utilised them as core layer in planar waveguide. It is envisaged that monitoring free volume and chain flexibility could induced changes in high refractive index and birefringence in the fabricated copolymer.

\section{EXPERIMENTAL}

\subsection{Materials}

4,4'-(hexafluoroisopropylidene) bis ( $p$-phenyleneoxy) dianiline (6BFIDDA, purity $>97.0 \%$ ), 3,3',4,4'-biphenyltetracarboxylic dianhydride (BPDA, purity $>97.0 \%$ ), and poly (dimethylsiloxane) bis (3-aminopropyl) terminated (ATPDMS, purity $>95.0 \%$ ) are used. Monomers were purchased from Sigma Aldrich (Malaysia) and used as received. N-methyl-2-pyrolidinone (NMP) and tetrahydrofuran (THF) used as solvent were purchased from Merck Darmstadt (Germany) and were freshly purified by distillation over calcium hydride. 


\subsection{Synthesis of Fluorinated Polyimide and Fluorinated Polyimide-siloxane Copolymer}

The synthesis of fluorinated polyimide is illustrated in Scheme 1. BPDA (1.47 g, $5 \mathrm{mmol}$ ) was dissolved in dry NMP in $50 \mathrm{ml}$, three-necked, round bottom flask equipped with a magnetic stirrer and stirred at room temperature under nitrogen. Then, 6BFIDDA ( $2.59 \mathrm{~g}, 5 \mathrm{mmol})$ was added into BPDA-NMP solution and stirred for $24 \mathrm{~h}$. A viscous fluorinated polyamic acid solution was obtained.

Fluorinated polyimide-siloxane copolymers, namely the PI-ATPDMS were synthesised as illustrated in Scheme 2. Using two-step method synthesis with BPDA (1.47 g, $5 \mathrm{mmol}$ ) was initially dissolved in dry NMP in $50 \mathrm{ml}$, three-necked, round bottom flask equipped with a magnetic stirrer and stirred at room temperature under nitrogen. Then, 6BFIDDA $(2.49 \mathrm{~g}, 4.8 \mathrm{mmol})$ was added into BPDA-NMP solution and stirred for $2 \mathrm{~h}$. ATPDMS $(0.5 \mathrm{~g}, 0.2 \mathrm{mmol})$ in THF solution was slowly dropped into BPDA-6BFIDDA-NMP solution at a rate of $100 \mu 1 \min ^{-1}$. Stirring the mixture for $24 \mathrm{~h}$ at room temperature afforded a viscous fluorinated polyamic acid intermediate solution.

Each film was prepared by solvent casting the solution onto the quartz glass substrate. The films were pre-baked in vacuum oven at $80^{\circ} \mathrm{C}$ for $24 \mathrm{~h}$. Then, film was taken out into furnace for curing and set up to heat stepwise, $100^{\circ} \mathrm{C}$ for $2 \mathrm{~h}$, $200^{\circ} \mathrm{C}$ for $2 \mathrm{~h}$, and $300^{\circ} \mathrm{C}$ for $2 \mathrm{~h}$. To avoid thermal stress on the film, the curing temperature from $300^{\circ} \mathrm{C}$ was slowly decreased to room temperature over $12 \mathrm{~h}$ upon completion.

\section{RESULTS AND DISCUSSION}

\subsection{Polyimide Series Synthesis}

As shown in Scheme 1, the synthesis of core layer follows generic polyimide method which initially involved polycondensation between the diamine (BPDA) and the dianhydride (6FIDDA) monomers to produce a polyamic acid intermediate followed by dehydration step affording the final polyimide product. For PIATPDMS synthesis, during the polyamic acid intermediate step, ATPDMS was added at a controlled rate of dropping $\left(0.5 \mu \mathrm{ml} \mathrm{s}^{-1}\right)$ to affect pseudo-dilution effect for nucleophilic substitution of amine onto the remaining anhydride group of polyamic acid. This is made possible by using a 2:1 ratio of the BPDA to 6FIDDA as opposed to that of the core layer synthesis at 1:1 ratio. See Scheme 2. 


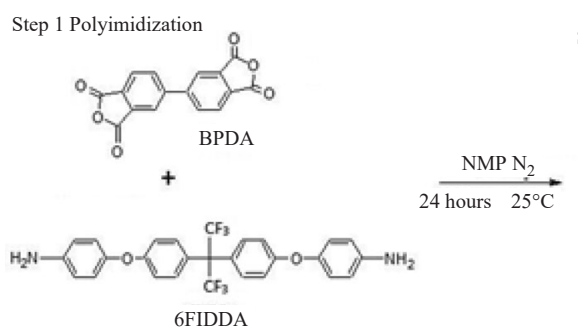

Step 2 Polyimidization

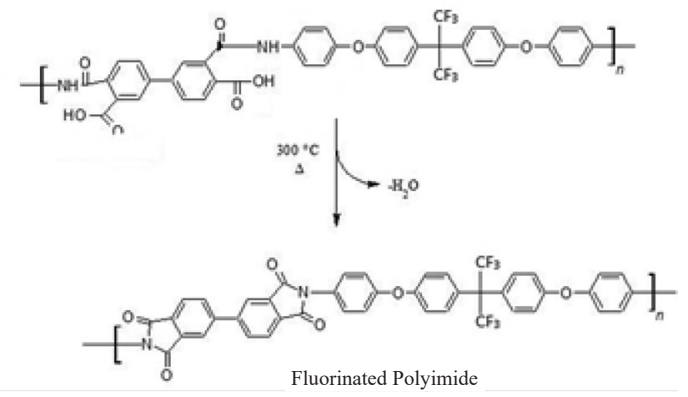

Scheme 1: Synthesis of fluorinated polyimide.

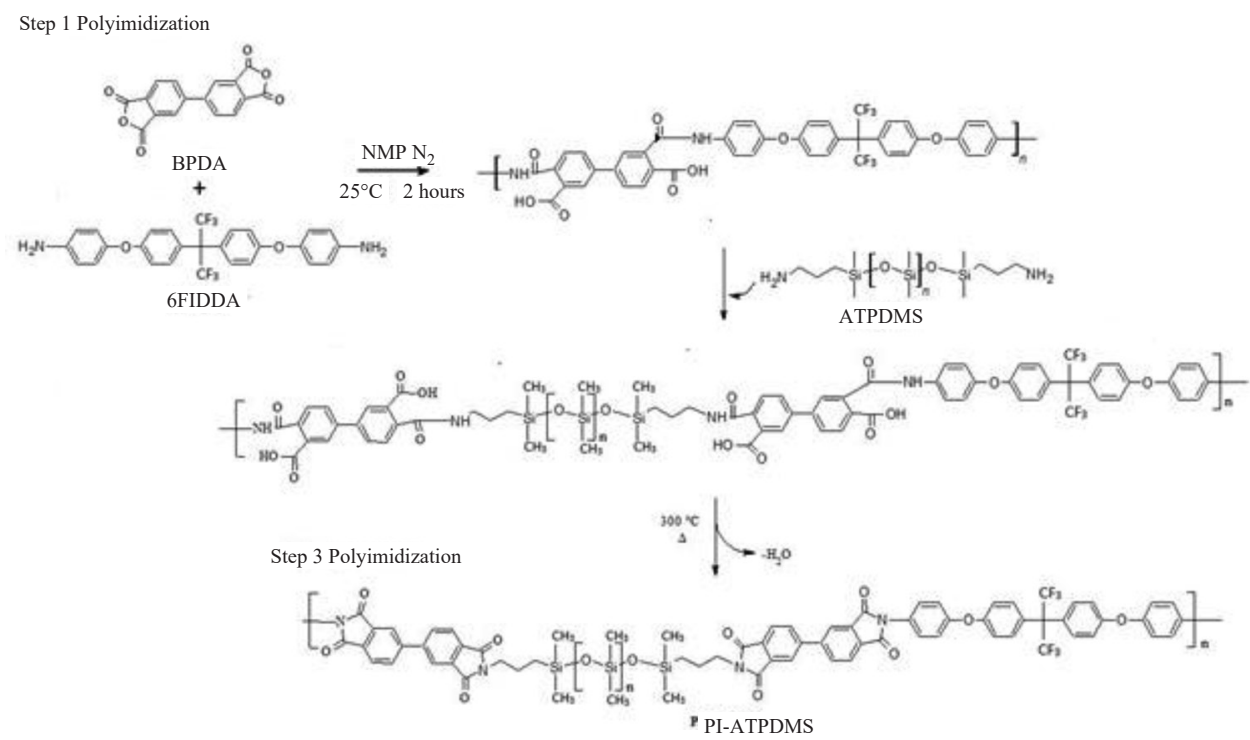

Scheme 2: Synthesis of fluorinated polyimide-siloxane copolymer.

FTIR spectra in Figure 1 confirm the chemical structure of both fluorinated polyimides. The absence of the peak at region $3450 \mathrm{~cm}^{-1}$ for all spectra implied a fully imidized product. They display the presence of strong and sharp peak at region $1750-1800 \mathrm{~cm}^{-1}$ corresponding to $\mathrm{C}=\mathrm{O}$ bonds. Notably PI-ATPDMS spectra show the present of broad and strong peak at region $700-1080 \mathrm{~cm}^{-1}$ corresponding to the Si-O-Si group which is absent in the PI spectrum. These results confirm the successful synthesis of the intended final products. 


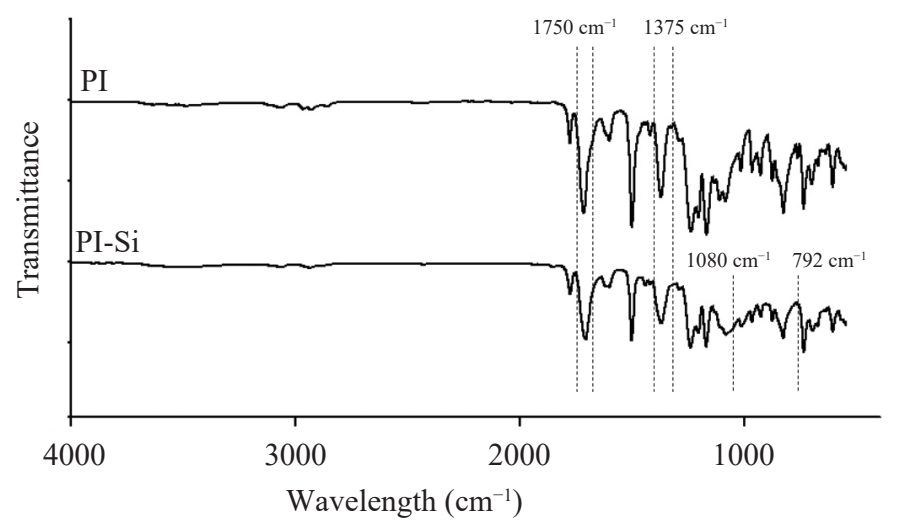

Figure 1: FTIR spectra of PI and PI-ATPDMS.

The molecular structures of PI and PI-ATPDMS were further characterised by ${ }^{1} \mathrm{H}-\mathrm{NMR}$ in DMSO- $d_{6}$ as shown in Figure 2.

(a)
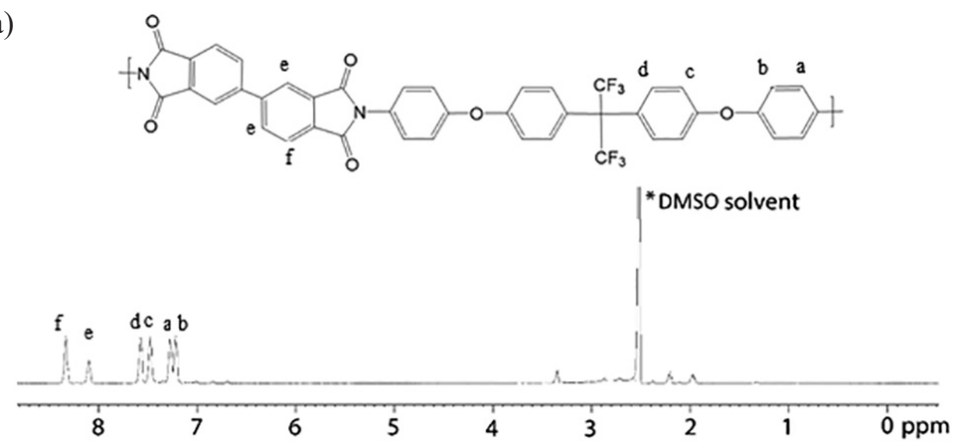

(b)
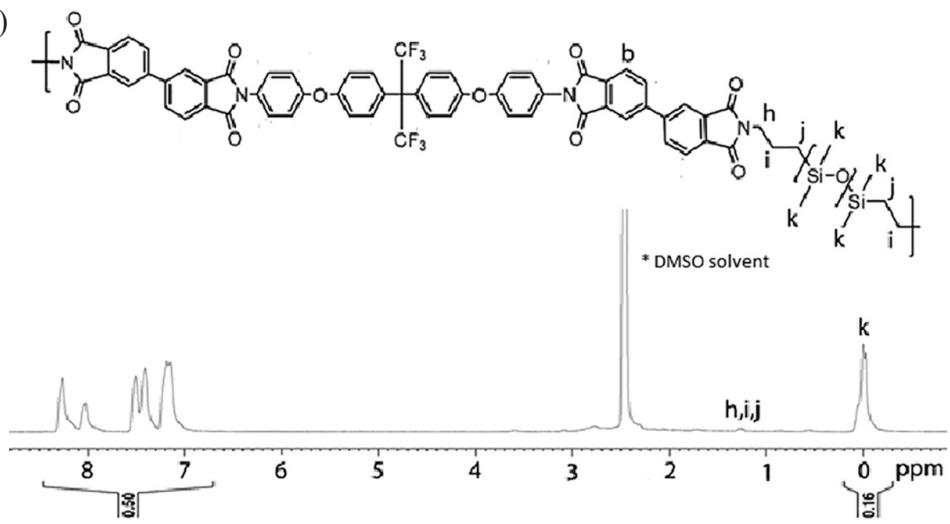

Figure 2: Illustrations of (a) ${ }^{1} \mathrm{H}-\mathrm{NMR}$ spectrum of PI, and (b) ${ }^{1} \mathrm{H}-\mathrm{NMR}$ spectrum of PI-ATPDMS. 
The ${ }^{1} \mathrm{H}-\mathrm{NMR}$ for all spectra reveals the signals for all aromatic protons in the region $6.8-8.5 \mathrm{ppm}$. This region appears almost similar peak pattern among the two polymer spectra as they are derived from similar aromatic precursors. In the case of PI-ATPDMS, an additional peak occurred at region $0.0-0.05 \mathrm{ppm}$ as well as a small peak at region $1.3 \mathrm{ppm}$ corresponding to the protons derived from the ATPDMS.

\subsection{Optical Properties}

\subsubsection{Transparency and refractive index}

Transparency of polyimide films were studied by using transmission UV-Vis spectroscopy as illustrated in Figure 5. PI and PI-ATPDMS showed good optical transparency with cut-off absorption wavelength in the range $374-380 \mathrm{~nm}$ respectively and reaching to almost $90 \%$ transmission beyond visible range of radiation. Under visible light, the materials appear light yellow. The high transmission could be attributable to the bulky and electron withdrawing -CF3 group in diamine segments effectively reducing charge transfer complex (CTC) between chains through steric hindrance and inductive effect. ${ }^{16}$ The incorporation of siloxane segment affects a slight decrease in transmission. This could be due to increase in flexibility of polyimide chain resulting in higher probability for lateral stacking of aromatic moiety of imide group in forming the charge transfer complex.

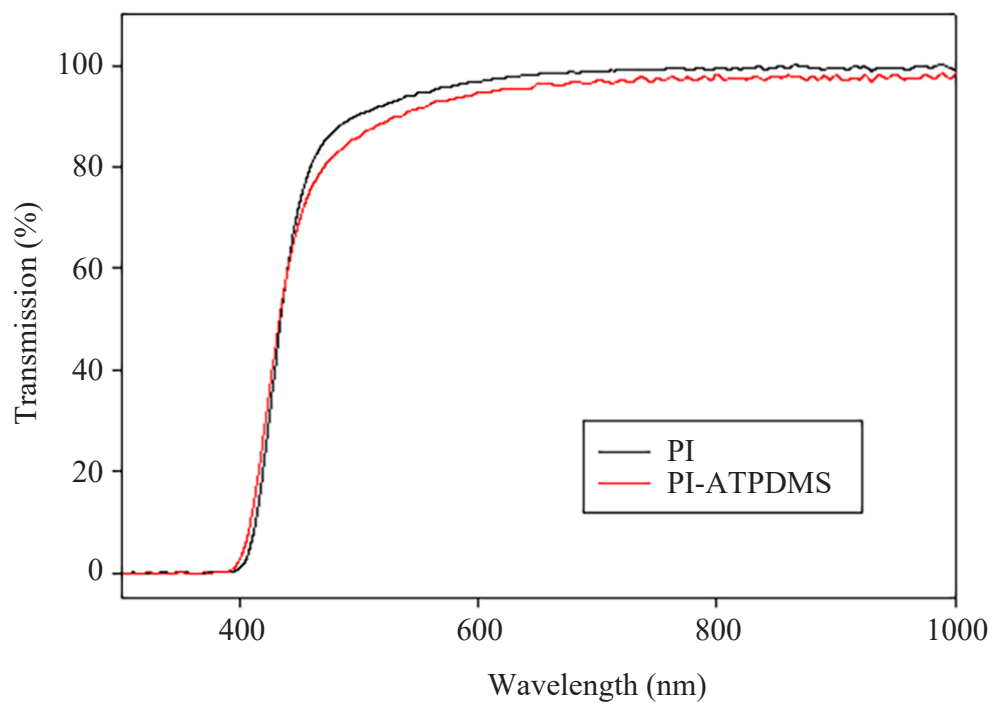

Figure 5: UV-Vis of polyimide in infrared region $(400 \mathrm{~nm})$ to visible region $(1000 \mathrm{~nm})$. 
Refractive indices of synthesised materials were measured using prism coupler. In Table 1, refractive index at $1550 \mathrm{~nm}$ of PI recorded a higher value than PIATPDMS in both transverse electric (TE) and transverse magnitude (TM) mode. The samples contain low polarizability substituted fluorine which induced low refractive indices compared to non-fluorinated commercial polyimide. However, the samples copolymerised with siloxane units displayed a further decrease in refractive index. This was attributable to the increase in free volume from the bulky and flexible siloxane segment in the polymer chain. The increase in free volume effectively reduced the polarizability group per unit volume. ${ }^{7,8}$ Both polyimides showed a minimal birefringence effect in the range of 0.008 to 0.013 . Of note, that of PI-ATPDMS displayed a lower birefringence than PI. Birefringence is related to thin films optical anisotropy.$^{17}$ PI has more rigid backbone structure which is co-planar due to high aromatic content ratio compared to PI-ATPDMS. Thus, it increases the anisotropy along its longitudinal direction. On the other hand, PI-ATPDMS showed a lower birefringence which is attributable to the chain flexibility of the copolymer. With the presence of bulky siloxane segment, this induced a higher free volume resulting in higher flexibility to isotropically rearrange irrespective of the rigidity of polyimide plane segment. Having low birefringence are very important for optical waveguide application which requires a very low polarization dependent loss. ${ }^{18}$ Table 1 summarises the optical properties of the synthesised polymers.

Table 1: Refractive indices, birefringence and surface roughness of polyimide films.

\begin{tabular}{lcccccc}
\hline \multirow{2}{*}{ Polymer } & \multicolumn{2}{c}{ Refractive index, $n$} & \multirow{2}{*}{ Birefringence, $\Delta n=n_{T E}-n_{T M 1}$} & \multicolumn{2}{c}{ Surface roughness } \\
\cline { 2 - 3 } & TE mode & TM mode & & $\mathrm{R}_{\mathrm{a}}(\mathrm{nm})$ & RMS (nm) \\
\hline PI & 1.598 & 1.585 & 0.013 & 1.605 & 2.328 \\
PI-ATPDMS & 1.550 & 1.542 & 0.008 & 3.094 & 3.982 \\
\hline
\end{tabular}

\subsubsection{Optical transparency in NIR region}

Peaks as observed in NIR spectroscopy is not very prominent as it was derived from overtones and combination of fundamental IR, mainly from $\mathrm{C}-\mathrm{H}$ and $\mathrm{O}-\mathrm{H}$ bonds. However, distinct peak characterisation could be observed in the spectrum in this work as shown in Figure 6. PI has a significant harmonic absorption in the region of 1200-1600 nm. Since the PI is devoid of any C-H bond, the absorption could be safely attributed to that of water molecules which might have been adsorbed onto the polymer surface. ${ }^{19}$ Such an adsorption effect of water molecule would be minimal in the case of PI-ATPDMS as they are highly hydrophobic due the presence of siloxane segment. This effect can be clearly seen with the diminished absorption peak particularly at $1550 \mathrm{~nm}$ radiation. Incorporation of $\mathrm{C}-\mathrm{F}$ bonds 
might also affect a shift in harmonic absorption to higher wavelength. ${ }^{15}$ Therefore, the optical transparency of the copolymers in the NIR region is significantly improved and they potentially show a better performance as the optical waveguide compared to conventional fluorinated PI.

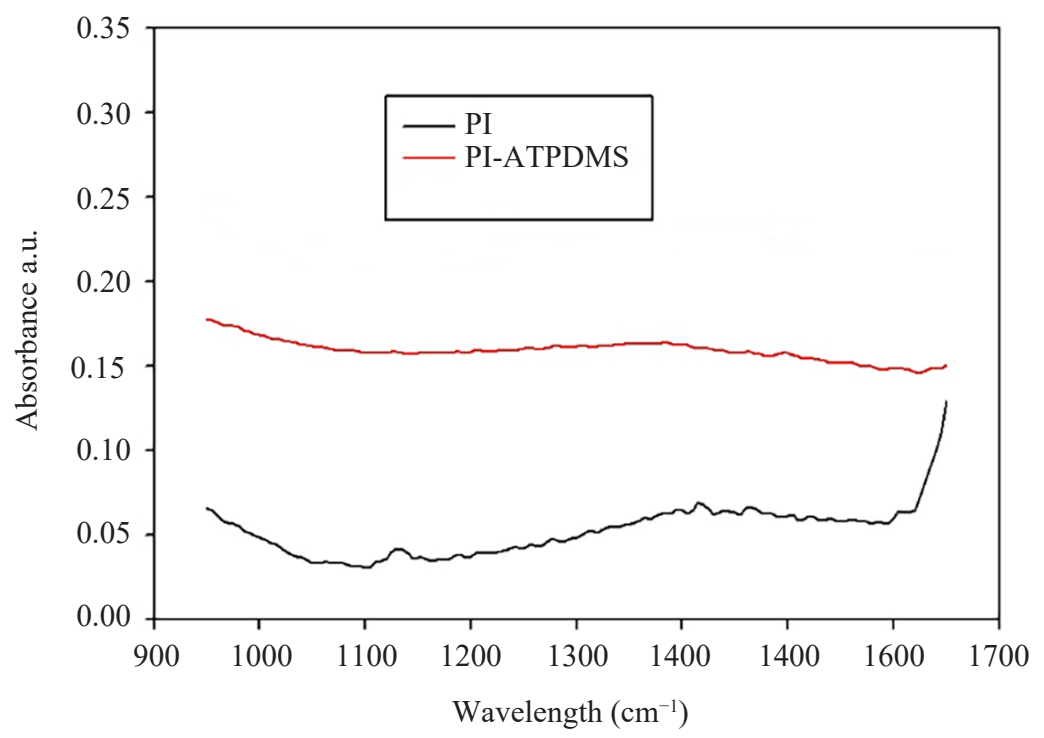

Figure 6: Near infrared spectra of PI and PI-ATPDMS.

\section{OPTICAL LOSS}

Optical transmission behaviour for synthesised polyimide and its copolymer was studied by fabricating single mode planar waveguides. Optical loss measured using prism coupler displayed the respectable low loss in the range 0.020 $0.066 \mathrm{~dB} \mathrm{~cm}^{-1}$ at $1550 \mathrm{~nm}$ radiation as shown in Table 2. A work on pure PDMS materials recorded the optical loss of $<0.05 \mathrm{~dB} \mathrm{~cm}^{-1}$ at $850 \mathrm{~nm}$ and $1.1 \mathrm{~dB} \mathrm{~cm}^{-1}$ at $460 \mathrm{~nm}$. These works make use of different geometrical design of the device but a rough reference can be presumed. ${ }^{20,21}$ The copolymers synthesised in the present work recorded a higher optical loss compared to pure polyimide.

Table 2: Optical loss for both planar and channel waveguide.

\begin{tabular}{lc}
\hline Sample & Planar waveguide $\left(\mathrm{dB} \mathrm{cm}^{-1}\right)$ \\
\hline PI & 0.020 \\
PI-ATPDMS & 0.042 \\
\hline
\end{tabular}


Optical loss at radio frequency can be related to various intrinsic features found in the material, namely absorption at NIR region, refractive indices of core and clad layers and birefringence, as well as extrinsic factors such as surface roughness, voids between core and clad interfaces, and water traces adsorbed onto the material surface. As shown in Table 2, the siloxane-polyimide copolymer recorded a higher loss than the pure polyimide despite the former revealing a lower transmission loss in the NIR spectrum of Figure 6, particularly at $1550 \mathrm{~nm}$. This contradiction could be due to extrinsic factors which include surface roughness and voids. Surface roughness of the polyimide samples were analysed using AFM with images as presented in Figure 7.
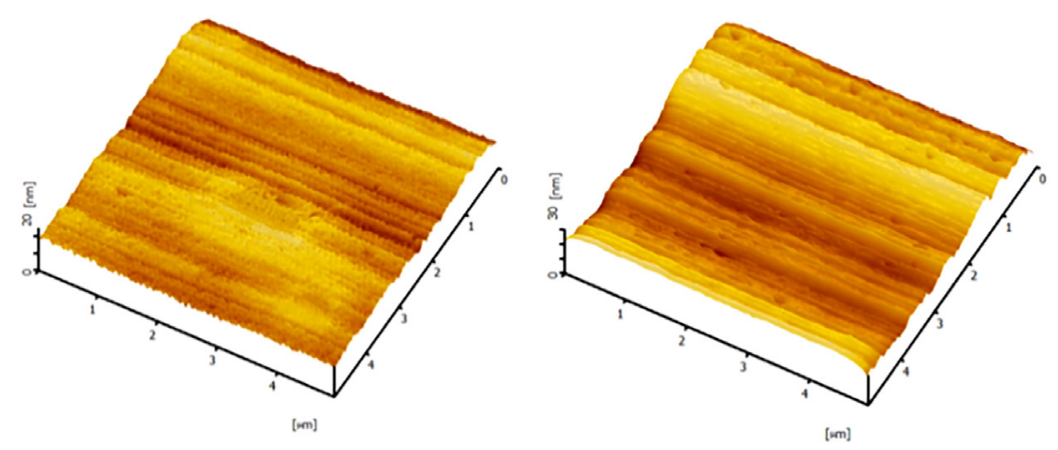

Figure 7: 3D AFM images of (a) PI, and (b) PI-ATPDMS.

The surface roughness was based on the roughness average (RA) and roughness means square (RMS) values of three-dimensional AFM pictures of PI and PIATPDMS. Based on Table 1, PI showed lower value of RA and RMS compared to PI-ATPDMS. For comparison, an n-alkyl ended of liquid crystal aromatic polyimide synthesised by Lee et al. displayed a surface roughness in the range of $0.5-0.7 \mathrm{~nm} \mathrm{rms.}{ }^{22}$ Generally, an increase in surface roughness affect an increase in radiation loss as the result of scattering arises from voids, defect and uneven surface texture..$^{23,24}$ Thus, the high roughness displayed by PI-ATPDMS surface could account for high loss in the waveguide compared to the pure polyimide. The higher roughness of polyimide siloxane copolymer could be attributable to inhomogeneity in the copolymer surfaces due to different type of polymer composition whose effect is particularly prominence at the nanoscale dimension. In addition, when the light input passed through the rough surface, it can cause backscattering over similar large angles resulting in increased input coupling loss. The influence of the waveguide surface roughness on scattering loss also depends on refractive index based on the concept of light trapping. ${ }^{24}$ Optimising light trapping is obtained by achieving the smallest reflectance, which invariably leads to small birefringence. 


\section{CONCLUSION}

In this work, a few conclusions can be drawn. Fluorinated polyimide and polyimide-co-polysiloxane were successfully synthesised for use in fabrication of single mode planar waveguide. The materials showed excellent optical properties in which polyimide-co-polysiloxane displayed low absorption in NIR region. Low polarizability effect of flourine incorporated into the synthesised material induced low refractive index. The introduction of siloxane moiety into the synthesised materials affect low birefringence. Optical loss is mostly attributed to surface roughness leading to voids and cracks between interfaces.

\section{ACKNOWLEDGEMENTS}

The authors gratefully acknowledge financial support from the Collaborative Research in Engineering, Science and Technology (CREST) project no. P29C1-14 in accomplishing this project.

\section{REFERENCES}

1. Rezem, M. et al. (2016). Fabrication and sensing applications of multilayer polymer optical waveguides. Proced. Technol., 26, 517-523, https://doi.org/10.1016/j. protcy.2016.08.064.

2. Flipsen, A. J. et al. (1998). Polymer optical fiber with high thermal stability and low optical losses based on novel densely crosslinked polycarbosiloxanes. J. Appl. Polym. Sci., 67(13), 2223-2230. https://doi.org/10.1002/(SICI)10974628(19980328)67:133.0.CO;2-0

3. Liu, Y., Yao, H. \& Zhang, Y. (2013). Synthesis of crosslinkable fluorinated linearhyperbranched copolyimides for optical waveguide devices. J. Appl. Polym. Sci., 127(3), 1834-1841, https://doi.org/10.1002/app.37905.

4. Cao, Z. et al. (2013). Crosslinkable fluorinated hyperbranched polyimide for thermo-optic switches with high thermal stability. J. Appl. Polym. Sci., 127(1), 607-611, https://doi.org/10.1002/app.37846.

5. Han, K. et al. (2002). Low-loss passive polymer waveguides by using chlorofluorinated polyimides. J. Appl. Polym. Sci., 74(1), 107-112.

6. Matsuura, T. et al. (1994). Polyimides derived from 2,2'-Bis(trifluoromethyl)-4,4'diaminobiphenyl. 4. Optical properties of fluorinated polyimides for optoelectronic components. Macromol., 27(22), 6665-6670, https://doi.org/10.1021/ ma00100a061.

7. Eldada, L. \& Shacklette, L. W. (2000). Advances in polymer integrated optics. IEEE J. Sel. Top. Quant. Electr., 6(1), 54-68, https://doi.org/10.1109/2944.826873.

8. Hougham, G., Tesoro, G. \& Viehbeck, A. (1996). Influence of free volume change on the relative permittivity and refractive index in fluoropolyimides. Macromol., 29(10), 3453-3456, https://doi.org/10.1021/ma9503423. 
9. Othman, M. B. H., Ang, N. S M. \& Md Akil, H. (2011). Dependence of the dielectric constant on the fluorine content and porosity of polyimides. J. Appl. Polym. Sci., 121, 3192-3200, https://doi.org/10.1002/app.33837.

10. Ghosh, M. \& Mittal, K. L. (2009). Polyimides: Fundamentals and applications. London: Taylor \& Francis.

11. Brown, H. R. (1991). A molecular interpretation of the toughness of glassy polymers. Macromol., 24(10), 2752-2756, https://doi.org/10.1021/ma00010a018.

12. Brown, H. R. et al. (1988). Diffusion and self-adhesion of the polyimide PMDAODA. Polym. J., 29(10), 1807-1811.

13. Cook, R. F. (2003). Adhesion between immiscible polymers correlated with interfacial entanglements. Macromol., 36(8), 2808-2815, https://doi.org/10.1021/ ma020789.

14. Hegde, S. G. et al. (2010). Optical loss changes in siloxane polymer waveguides during thermal curing. J. Appl. Polym. Sci., 106(4), 2320-2327, https://doi. org/10.1002/app.26945.

15. Ando, S. (2006). Optical properties of fluorinated polyimides and their applications to optical components and waveguide circuits. J. Photopolym. Sci. Technol., 17(2), 219-232.

16. Tapaswi, P. K. et al. (2015). Synthesis and characterization of highly transparent and hydrophobic fluorinated polyimides derived from perfluorodecylthio substituted diamine monomers. J. Polym. Sci. A Polym. Chem., 53(3), 479-488, https://doi. org/10.1002/pola.27461.

17. Chao, C. C. \& Wen, C. C. (2002). Synthesis and optical properties of polyimidesilica hybrid thin films. Mater. Chem. Phys., 14(10), 4242-4248, https://doi. org/10.1021/cm0202310.

18. Habib, M. A. et al. (2019). Extremely high birefringent and low loss microstructure optical waveguide: Design and analysis. Opt. Commun., 446, 93-99, https://doi. org/10.1016/j.optcom.2019.04.060.

19. Workman, J. J. \& Weyer, L. (2008). Practical guide to interpretive near-infrared spectroscopy. Ang. Chem. Int. Ed., 47(25), 4628-4629, https://doi.org/10.1002/ anie. 200885575.

20. Cai, D. K. et al. (2008). Optical absorption in transparent PDMS materials applied for multimode waveguides fabrication. Opt. Mater. (Amst), 30(7), 1157-1161, https://doi.org/10.1016/j.optmat.2007.05.041.

21. Cai, Z. et al. (2013). A new fabrication method for all-PDMS waveguides. Sens. Actuat. A Phys., 204, 44-47, https://doi.org/10.1016/j.sna.2013.09.019.

22. Lee, S. W. et al. (2005). Role of the n-alkyl end of bristles in governing liquid crystal alignment at rubbed films of brush polymer rods. Macromol., 38(10), 4331-4338, https://doi.org/10.1021/ma047856z.

23. Zhong, N. et al. (2013). Effects of surface roughness on optical properties and sensitivity of fiber-optic evanescent wave sensors. Appl. Opt., 52(17), 3937, https://doi.org/10.1364/ao.52.003937.

24. Scholtz, L., Ladanyi, L. \& Mullerova, J. (2014). Influence of surface roughness on optical characteristics of multilayer solar cells. Adv. Electr. Electron. Eng., 12(6), 631-638, https://doi.org/10.15598/aeee.v12i6.1078. 